\title{
Mental Distress Associated with Air Quality Vulnerability During COVID-19
}

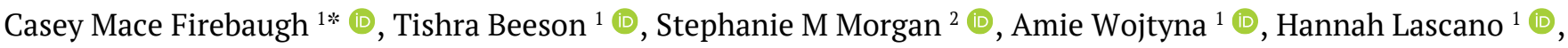 \\ Melody Madlem ${ }^{1}$ (D)
}

\footnotetext{
${ }^{1}$ Department of Health Sciences, Central Washington University, Ellensburg, WA, USA

${ }^{2}$ Department of General Education, Ameritech College, Provo, UT, USA

*Corresponding Author: caseyandfiske@gmail.com
}

Citation: Mace Firebaugh, C., Beeson, T., Morgan, S., Wojtyna, A., Lascano, H. and Madlem, M. (2022). Mental Distress Associated with Air Quality Vulnerability During COVID-19. European Journal of Environment and Public Health, 6(1), em0103. https://doi.org/10.21601/ejeph/11674

\section{ARTICLE INFO}

Received: 27 Nov. 2021

Accepted: 8 Jan. 2022

\begin{abstract}
Yakima County, Washington is an area with prolonged exposure to poor air quality (PM 2.5) and has been one of the hardest hit counties in cases per capita of COVID-19 in the Western US. The physical health impacts of poor air quality exposure and COVID-19 have been well documented. However, the mental health impacts of these concurrent exposures are unknown. A pilot study $(\mathrm{n}=232)$ surveyed households using random-digit-dialing (RDD) in Yakima, County in Dec 2020-Jan 2021 to understand the spread of COVID-19 in vulnerable communities. Air quality behaviors and contexts including home filtration systems and use of community shelters during poor air quality events were measured. Mental distress was measured by the John Hopkins's Mental Distress COVID-19 Community Response Survey. Descriptive data analysis along with Spearman's rank correlation analysis were performed. Nearly half of the sample $(45.3 \%)$ did not have access to air quality mitigation measures in their homes. The majority of the sample (54.3\%) reported wanting to access clean air shelters during major air quality events such as the smoke and wildfire season of 2020. Participants who were unable to mitigate poor air quality in their households as well as those who were unable to access community clean air shelters were observed to have higher levels of mental distress $(\mathrm{p}<.05)$. This study adds to the body of evidence that environmental exposures play a significant role in mental health and that compounding impacts of climate change should be studied more in depth. Household interventions should be explored as COVID-19 has brought community protection measures to a halt, while climate change induced natural disasters will only increase in the future.
\end{abstract}

Keywords: COVID-19, air quality $\mathrm{PM}_{2.5}$, mental health, mitigation, climate change

\section{INTRODUCTION}

Yakima County, Washington displayed the highest COVID19 infection rate among any county on the West Coast of the United States in early Spring 2020 (Geranios, 2020) with an initial peak of over 700 cases per 100,000 populations during June of 2020 (Washington State Coronavirus Response, 2021). Simultaneously, Yakima municipality has been ranked as the $5^{\text {th }}$ worst and Yakima County as $13^{\text {th }}$ worst for short-term particle air pollution in the United States (American Lung Association, 2021). This increased environmental exposure may exacerbate vulnerability to COVID-19 disease and lead to poor respiratory outcomes (Azuma et al., 2020; Ching and Kajino, 2020; Wu et al., 2020).

Environmental changes can increase mental distress and feelings of uncertainty and insecurity (Usher et al., 2020). The impact of the COVID-19 pandemic is far-reaching and isolation, loss of livelihood, misinformation, and lack of access to resources have resulted in a myriad of mental health consequences (Fiorillo and Gorwood, 2020; Killgore et al., 2020; Kumar and Nayar, 2020; Ornell et al., 2020). Depression, anxiety, substance abuse, self-harm, eating disorders, and suicide have increased in severity and treatment episodes since the onset of COVID-19 (Czeisler et al., 2020; McKnightEily et al., 2021; Son et al., 2020). Additionally, perceptions of low quality of life and environmental stressors can decrease one's ability to cope with mental distress (Chwaszcz et al., 2021).

The Yakima County region has experienced notable deficits in air quality over the past decade, in particular in fine particulate matter $\left(\mathrm{PM}_{2.5}\right)$ (American Lung Association, 2019; Firebaugh et al., 2020; Washington Smoke Information, 2020). $\mathrm{PM}_{2.5}$ is defined as suspended particulate matter that is smaller in aerodynamic diameter than $2.5 \mu \mathrm{m}$; it is mainly made up of products from incomplete combustion of fuels, and some agricultural and industrial activities (World Health Organization, 2017). Yakima County’s air quality is negatively 
impacted by PM emissions from episodic wildfires in the summer months, and wood stoves used for home heating during cold winter months (VanderSchelden et al., 2017). In addition, ammonium and secondary aerosol production from animal emissions have contributed to poor air quality and motivated several recent studies on pediatric asthma in the region (Loftus et al., 2015; Masterson et al., 2020). Upon inhalation, $\mathrm{PM}_{2.5}$ adversely impacts the respiratory and cardiovascular systems, even causing premature death (World Health Organization, 2017). Thus, $\mathrm{PM}_{2.5}$ exposures may correspond directly to pulmonary function and risk factors for COVID-19 as a respiratory infectious disease. Research conducted early in the pandemic found that higher levels of PM were significantly positively associated with COVID-19 morbidity and mortality (Wu et al., 2020). A recent paper was able to calculate the attributable risk of COVID-19 death related to long-term PM exposure. Using satellite data of $\mathrm{PM}_{2.5}$, the researchers found that $15 \%$ of all COVID-19 deaths in North America were attributable to long-term $\mathrm{PM}_{2.5}$ exposures, $50 \%$ or more of which was attributable to human causes (Pozzer et al., 2020). The study also found that even small increases in $\mathrm{PM}_{2.5}$ contributed to morbidity and mortality (Pozzer et al., 2020).

\section{Indoor Air Quality and COVID-19 at the Household Level}

To date, the interaction of indoor $\mathrm{PM}_{2.5}$ and COVID-19 vulnerability and health outcomes remain unknown (Du and Wang, 2020; Espejo et al., 2020). In addition, little is published on changes in indoor air quality resulting from COVID-19 public policies and subsequent modified social and environmental conditions. One recent study on indoor air quality in public housing units in Spain during the initial 45day lockdown in COVID-19 hotspots found that due to increased time spent indoors, indoor air pollution significantly increased by $12 \%$ for $\mathrm{PM}_{2.5}$ and by $559 \%$ for volatile organic compounds (Dominguez-Amarillo et al., 2020). These air quality deficits were found despite significantly improved outdoor air quality and to be associated with a lack of suitable ventilation and more intensive use of cleaning products and disinfectants (Dominguez-Amarillo et al., 2020). The Environmental Protection Agency (EPA) estimates that the average American spends $90 \%$ of their lives indoors, where PM levels are estimated to be 2-to-5 times higher in concentration than the surrounding outdoor area (Environmental Protection Agency, 2020). During the COVID-19 pandemic, people spend even more time at home, according to Google's COVID-19 Community Mobility Reports (Google, n.d.). Washington State residents spent significantly more time at home (ranging from $9 \%$ to $50 \%$ ) compared to pre-pandemic time (Google, n.d.). If current projections regarding wildfires, indoor and outdoor air quality, and continued COVID-19 infections in the US are confirmed, Yakima County residents, including those who will be diagnosed with COVID-19, will be exposed to disproportionately worse air quality while they attempt to recover from the pandemic conditions.

While household $\mathrm{PM}_{2.5}$ is associated with cardiorespiratory, pediatric, and maternal disease outcomes (Lee et al., 2020), the link between indoor $\mathrm{PM}_{2.5}$, the COVID-19 conditions and mental health outcomes are relatively unknown. However, research on previous natural disasters such as wildfires or manmade disasters such as war-time conflicts have demonstrated that these events are associated with psychological distress, both acute and long-term. Previous studies on these events have identified salient factors associated with the incidents and post-disaster response measures that have the potential to mitigate adverse effects (Beaglehole et al., 2018). However, the novelty of COVID-19 interacting in a community with significant socio-economic and environmental disparities has not been assessed for factors associated with mental distress in this phenomenon. This study aims to investigate the association between air pollution mitigation factors and mental distress during COVID-19 conditions.

\section{METHODS}

\section{Study Design and Sampling}

In 2020, a study on the spread and severity of COVID-19 in vulnerable communities was launched to intermittently survey residents of Yakima County, Washington. This large-scale study examined comprehensive factors related to COVID-19 prevention and spread, including prevention behaviors, knowledge, demographic factors, mental and physical health impacts. The presented results herein are from a subset of the pilot wave $(n=232)$. The pilot wave was conducted during the period of (November 2020-January 2021) while the region was in a "Phase 1" community restriction (also referred to as a "lockdown"); the most restrictive phase for school and business openings, emphasizing the Washington State Department of Health's message to "stay home, stay safe." Data collection for the larger-scale study is ongoing. A dualframe RDD methodology was employed to conduct landline and mobile phone interviews with individuals in English or Spanish, with the household member on the phone being aged 18 -and over providing over the phone consent to participate in a larger study.

\section{Measures}

COVID-19 measures from the JHU COVID-19 Community Response Survey included the Mental Health Impacts section which is a 15-item scale with different areas of stress/distress related to the experience of COVID-19 (Mehta, 2020). The measure includes but is not limited to fear of health consequences for self or loved ones, the mental disturbances to sleep and daily life, the economic worries presented by the COVID-19 pandemic over the past 14-days. The measures included responses in a Likert scale ranging from "strongly disagree" "disagree" "neutral" "agree” and "strongly agree." The measure responses were collapsed "strongly disagree" "disagree" "neutral" together and "agree" and "strongly" agree together to form "yes" "no" dichotomous variables. The research team created an original survey instrument about air quality health behaviors adapted from previous county air quality surveys conducted regionally. These questions included questions about respondents' primary and secondary sources of indoor heat, utilization of in-home air purifiers, and intention to use community clean air shelters during COVID19 conditions. 
Table 1. Individual construct mental health distress responses of study sample

\begin{tabular}{|c|c|c|}
\hline \multirow{2}{*}{ Measure question } & \multicolumn{2}{|c|}{ Yes responses } \\
\hline & $\mathbf{n}$ & $\%$ \\
\hline I have had difficulties sleeping since March 1, 2020. & 73 & 31.5 \\
\hline I have had difficulties concentrating since March 1, 2020. & 56 & 24.1 \\
\hline I feel anxious thinking about the COVID-19 pandemic. & 125 & 53.9 \\
\hline I feel overwhelmed thinking about the COVID-19 pandemic. & 89 & 38.4 \\
\hline I am concerned I will get infected by the COVID-19 disease. & 134 & 57.8 \\
\hline I am concerned I will pass the COVID-19 disease onto someone else. & 141 & 60.8 \\
\hline I am concerned I will have to go to the hospital if I get the COVID-19 disease. & 148 & 63.8 \\
\hline I worry whether I will have to go into quarantine whether I get COVID-19 or not. & 98 & 47.2 \\
\hline I worry someone in my direct environment (family, friends, and colleagues) will get COVID-19 disease. & 171 & 73.7 \\
\hline I worry someone in my direct environment (family, friends, and colleagues) will die from COVID-19 disease. & 167 & 72.0 \\
\hline I worry about money because of the COVID-19 pandemic. & 114 & 49.1 \\
\hline I worry about having enough food because of the COVID-19 pandemic. & 81 & 34.9 \\
\hline I worry about loss of income if I get COVID-19 disease. & 102 & 44 \\
\hline I worry about medical bills if I get COVID-19 disease. & 123 & 53 \\
\hline I am spending more money because of the COVID-19 pandemic. & 92 & 39.7 \\
\hline
\end{tabular}

\section{Data Analysis}

Descriptive data analysis for all the variables included in the analyses are reported, along with the demographic characteristics of the sample. Due to the small sample size and non-normal distribution of the demographic variables, nonparametric testing (Spearman's rho) was used in the inferential analyses in this study, and we did not attempt to model any multivariable analyses. The measures used in the COVID-19 community response scale were developed/adapted specifically for utilization in the response to and study of the COVID-19 pandemic, a novel event. The scoring of such scales has little guidance, therefore for the mental health score, we report the descriptive data for each individual construct of the COVID-19 distress scale as well as the total score means of the sample. The individual constructs in the mental health impacts scales were analyzed individually as were total scores. In addition, we created a split sample in which those scoring 1-6 as having "lower distress" and those who have a total score of 7 or higher as having "higher distress." This dichotomous score was compared in a correlation analysis to the independent variables. This study was approved by the Central Washington University HSRC (not IRB).

\section{RESULTS}

\section{Demographic Findings}

In total, there were $(n=232)$ respondents aged 18 and over in the final study sample. The following section presents the demographic characteristics of the sample. $38.9 \%$ of the sample was aged 18-49, with the remaining percent of the sample (61.1\%) aged 50 and over. $56.5 \%$ of the respondents identified as female and $31.8 \%$ were male, $1.7 \%$ were nonbinary gender. The educational attainment of the sample included $37.9 \%$ who had high school graduation education or less, while the remaining $62.1 \%$ had some college training or higher education. While almost half of Yakima County identifies as Hispanic or Latino, only $42.7 \%$ of participants in this sample did. In the pilot study sample, $17.2 \%(n=40)$ of the respondents had at least one member of the household (including themselves) who had tested positive for COVID-19.

\section{Mental Health Descriptive Analysis}

Participants in this study were asked to complete the COVID-19 distress scale included in the John Hopkin's community response survey (Mehta, 2020). Total scores for the 15 -item scale ranged from $0-15$ with a mean of $7.4(\mathrm{SD}+/-4.2)$. (Table 1) presents the individual responses for the 15-point scale on mental health impacts of COVID-19.

\section{Air Quality Context Descriptive Analysis}

Most participants (57.8\%) used central or forced air in their homes. $3.4 \%$ of the sample used wood-burning as a primary source of heat and $26 \%$ used wood burning as a secondary source of heat. About a quarter (24.6\%) of participants reported having a HEPA filter device to assist in purifying their air. $15.1 \%$ had some other type of air purifier, and $18.1 \%$ recirculated air in their home air conditioning or heating system. Almost half of households (47.3\%). surveyed did not have any form of mitigation for poor air quality in their home. While more than half of Yakima County households surveyed had at least one form of poor air quality mitigation in their home (52.6\%), a smaller subset of those (7.3\%) reported using a combination of two-to-three forms of poor air quality mitigation. Still, $47.3 \%$ of households were without any mitigation tools in their home when poor air quality was present. Over half of respondents (52\%) reported that they would opt to utilize a clean air shelter during air quality events (such as wildfires), including $17 \%$ who reported having no access to in-home mitigation strategies.

\section{Inferential Findings}

Higher levels of mental distress included individuals in the upper half of the distress scales while community clear air measures meant those who intended to use clean air shelters but did not have access. In-home air quality mitigation included those who responded that had some type of air filtration system or some method used in their home that reduced poor air quality at the household level (self-reported). Lacking access to in-home or community clean air measures were positively associated with higher levels of mental distress during the COVID-19 pandemic $(\mathrm{p}<.05)$. 


\section{DISCUSSION}

Although it is difficult to make a direct comparison on the mental health distress scale used to assess the impact of COVID-19 versus typical population mental health monitoring, this study lays the groundwork for understanding the degree to which mental health distress is of significant concern in the target community who faces complex risk factors for respiratory illness, including COVID-19. In a previous community health assessment in $2017,13 \%$ of adults aged 18 and over living in Yakima reported having 14 or more days of poor mental health in the past 30 days (Washington State Department of Health, 2017). This study observes a high proportion of the population experiencing a significant number of mental distress symptoms and co-occurring needs around air quality mitigation that may otherwise exacerbate respiratory outcomes. While this study found an association between mental health distress and the lack of air quality mitigation efforts either at the individual household or community level, further research to understand this relationship-including multivariate analysis should be conducted. Other communities that are subject to high rates of COVID-19 and typical environmental pollution may be at risk for significant population levels of mental health distress including anxiety disorders, PTSD, depression or other psychological disturbances. Future research should continue to monitor these communities for these conditions.

The study's findings are consistent with previous research on disaster preparedness and response and mental health distress. When individual or community health resources, services, and supports are lacking, individuals are more at risk for acute and long-term mental distress (Beaglehole et al., 2018). A high proportion of the population has no household protection from poor air quality events yet is exposed to seasonal air quality events that increase the risk profile for respiratory illness. In Yakima County, and across much of Washington State in the summer of 2020, wildfire smoke events occurred in which there were 14 straight days of hazardous air quality. If air quality shelters will not be available in the summer/fall fire season, alternate plans should be coordinated with public health and community organizations to ensure that all households have some form of air quality mitigation.

The collateral impacts of climate change have been shown to yield a higher frequency and intensity of natural disasters including wildfires. Despite the general consensus among climate change experts, the necessary efforts to reduce these events in the short and mid-term do not appear to be imminent. Household-level interventions should be explored for vulnerable citizens in the short- and mid-term as they are most immediately and severely impacted by these events.

This study is limited by a small sample size and thus only limited inferences can be made from the findings of this research. However, the study sample skewed toward individuals who may have been more economically advantaged and less vulnerable in the target community. Therefore, these findings may have been even more pronounced in a more representative and vulnerable segment of the population. Findings within this study provide initial evidence to move research forward connecting air pollution and mental health, particularly in the pandemic context. As the response and recovery from COVID-19 and concurrent air quality events goes from acute to mid to long term, public, mental, and medical health professionals should be aware of the likelihood of ongoing mental distress in light of these events.

\section{CONCLUSIONS}

Populations in Yakima County are disproportionally affected by persistent poor air quality $\left(\mathrm{PM}_{2.5}\right)$ and high rates of COVID-19. This preliminary study demonstrated that those persons with less ability to mitigate their exposure to poor air quality are at risk of worse mental health outcomes in face of the COVID-19 pandemic. Environmental exposures will persist in this region and policy makers, public health, mental health, and general practitioners should consider individual or household level interventions as typical community response to fire and smoke. The findings of this study indicate a need to further investigate the synergy of these concurrent factors on mental health.

Author contributions: All co-authors have involved in all stages of this study while preparing the final version. They all agree with the results and conclusions.

Funding: This study was funded by the American Lung Association.

Acknowledgements: All authors wish to thank Ryan Arboleda, Vanessa Velaquez, and Arturo Contreras for translation and testing of the survey instrument used in this study. Sophia Rasmusson and Aly Cokl assisted with data collection efforts.

Declaration of interest: The authors declare that they have no competing interests.

Ethics approval and consent to participate: Not applicable. Availability of data and materials: All data generated or analyzed during this study are available for sharing when appropriate request is directed to corresponding author.

\section{REFERENCES}

American Lung Association. (2021). State of the air. American Lung Association, Chicago. Available at: https://www.lung.org/research/sota

Azuma, K., Yanagi, U., Kagi, N., Kim, H., Ogata, M. and Hayashi, M. (2020). Environmental factors involved in SARS-CoV-2 transmission: Effect and role of indoor environmental quality in the strategy for COVID-19 infection control. Environmental Health and Preventive Medicine, 25, Article number 66. https://doi.org/10.1186/ s12199-020-00904-2

Beaglehole, B., Mulder, R. T., Frampton, C. M., Boden, J. M., Newton-Howes, G. and Bell, C. J. (2018). Psychological distress and psychiatric disorder after natural disasters: systematic review and meta-analysis. The British Journal of Psychiatry, 213(6), 716-722. https://doi.org/10.1192/bjp. 2018.210 
Ching, J. and Kajino, M. (2020). Rethinking air quality and climate change after COVID-19. International Journal of Environmental Research and Public Health, 17(14), 5167. https://doi.org/10.3390/ijerph17145167

Chwaszcz, J., Palacz-Chrisidis, A., Wiechetek, M., Bartczuk, R. P., Niewiadomska, I., Wośko, P. and Sławska-Jaroszewska, P. (2021). The quality of life, resources, and coping during the first weeks of the COVID-19 pandemic in people seeking psychological counselling before the pandemic. International Journal of Occupational Medicine and Environmental Health, 34(2), 1-13. https://doi.org/10. 13075/ijomeh.1896.01700

Czeisler, M. É., Lane, R. I., Petrosky, E., Wiley, J. F., Christensen, A., Njai, R., Weaver, M. D., Robbins, R., FacerChilds, E. R., Barger, L. K., Czeisler, C. A., Howard, M. E. and Rajaratnam, S. M. W. (2020). Mental health, substance use, and suicidal ideation during the COVID-19 pandemicUnited States, June 24-30, 2020. Morbidity and Mortality Weekly Report, 69(32), 1049. https://doi.org/10.15585/ mmwr.mm6932a1

Domínguez-Amarillo, S., Fernández-Agüera, J., CesterosGarcía, S. and González-Lezcano, R. A. (2020). Bad air can also kill: Residential indoor air quality and pollutant exposure risk during the COVID-19 crisis. International Journal of Environmental Research and Public Health, 17(19), 7183. https://doi.org/10.3390/ijerph17197183

$\mathrm{Du}$, W. and Wang, G. (2020). Indoor air pollution was nonnegligible during COVID-19 lockdown. Aerosol and Air Quality Research, 20(9), 1851-1855. https://doi.org/10.4209 /aaqr.2020.06.0281

Environmental Protection Agency. (2020). Indoor air and Coronavirus (COVID-19). Available at: https://www.epa. gov/coronavirus/indoor-air-and-coronavirus-covid-19

Espejo, W., Celis, J. E., Chiang, G. and Bahamonde, P. (2020). Environment and COVID-19: Pollutants, impacts, dissemination, management and recommendations for facing future epidemic threats. Science of the Total Environment, 747, 141314. https://doi.org/10.1016/ j.scitotenv.2020.141314

Fiorillo, A. and Gorwood, P. (2020). The consequences of the COVID-19 pandemic on mental health and implications for clinical practice. European Psychiatry, 63(1), 1-2. https://doi.org/10.1192/j.eurpsy.2020.35

Firebaugh, C., Beeson, T., Wojtyna, A., Bravo, L., Everson, T., Johnson, J. and Saldana, A. (2020). A community case study on geographic, environmental, and social health disparities in COVID-19 disease: Yakima, Washington. Open Journal of Preventive Medicine, 10, 288-297. https://doi.org/10.4236/ojpm.2020.1011021

Geranios, N. K. (2020, May 4). County has highest rate of COVID-19 cases on West Coast. The Seattle Times. Available at: https://www.seattletimes.com/seattlenews/yakima-county-has-top-rate-of-coronavirus-caseson-west-coast/

Google. (n.d.). Covid-19 Mobility Reports. Available at: https://www.google.com/covid19/mobility/
Killgore, W. D. S., Cloonan, S. A., Taylor, E. C. and Dailey, N. S. (2020). Loneliness: A signature mental health concern in the era of COVID-19. Psychiatry Research, 290, 113117. https://doi.org/10.1016/j.psychres.2020.113117

Kumar, A. and Nayar, K. R. (2020). COVID-19 and its mental health consequences. Journal of Mental Health, 180(6), 817818. https://doi.org/10.1001/jamainternmed.2020.1562

Lee, K. K., Bing, R., Kiang, J., Bashir, S., Spath, N., et al. (2020). Adverse health effects associated with household air pollution: A systematic review, meta-analysis, and burden estimation study. The Lancet Global Health, 8(11), e1427e1434. https://doi.org/10.1016/S2214-109X(20)30343-0

Loftus, C., Yost, M., Sampson, P., Torres, E., et al. (2015). Ambient ammonia exposures in an agricultural community and pediatric asthma morbidity. Epidemiology, 26(6), 794801. https://doi.org/10.1097/EDE.0000000000000368

Masterson, E. E., Younglove, L. B., Perez, A., Torres, E., et al. (2020). The home air in agriculture pediatric intervention (HAPI) trial: Rationale and methods. Contemporary clinical trials, 96, 106085. https://doi.org/10.1016/j.cct.2020. 106085

McKnight-Eily, L. R., Okoro, C. A., Strine, T. W., Verlenden, J., et al. (2021). Racial and ethnic disparities in the prevalence of stress and worry, mental health conditions, and increased substance use among adults during the COVID19 pandemic-United States, April and May 2020. Morbidity and Mortality Weekly Report, 70(5), 162-166. https://doi.org/10.15585/mmwr.mm7005a3

Mehta. (2020). COVID-19 mental distress scale, John Hopkins Community Response Scale (COVID-19).

Ornell, F., Schuch, J. B., Sordi, A. O. and Kessler, F. H. P. (2020). "Pandemic fear" and COVID-19: Mental health burden and strategies. Brazilian Journal of Psychiatry, 42(3), 232-235. https://doi.org/10.1590/1516-4446-2020-0008

Pozzer, A., Dominici, F., Haines, A., Witt, C., Münzel, T. and Lelieveld, J. (2020). Regional and global contributions of air pollution to risk of death from COVID-19. Cardiovascular Research, 116(14), 2247-2253. https://doi.org/10.1093/ cvr/cvaa288

Son, C., Hegde, S., Smith, A., Wang, X. and Sasangohar, F. (2020). Effects of COVID-19 on college students' mental health in the United States: Interview survey study. Journal of Medical Internet Research, 22(9), e21279. https://doi.org/ $10.2196 / 21279$

Usher, K., Durkin, J. and Bhullar, N. (2020). The COVID-19 pandemic and mental health impacts. International Journal of Mental Health Nursing, 29(3), 315-318. https://doi.org/ 10.1111/inm.12726

VanderSchelden, G., de Foy, B., Herring, C., Kaspari, S., VanReken, T. and Jobson, B. (2017). Contributions of wood smoke and vehicle emissions to ambient concentrations of volatile organic compounds and particulate matter during the Yakima wintertime nitrate study. Journal of Geophysical Research: Atmospheres, 122(3), 1871-1883. https://doi.org/10.1002/2016JD025332 
Washington Smoke Information. (2020, September 23). Smoky siege: A look back at the smoke storm of 2020. Available at: https://wasmoke.blogspot.com/2020/09/smoky-siegelook-back-at-smoke-storm-of.html

Washington State Coronavirus Response. (2021, April 12). Roadmap to recovery metrics. Available at: https://coronavirus.wa.gov/sites/default/files/202104/421-006-RoadmapToRecovery-20210412.pdf

Washington State Department of Health. (2017). Yakima cmmunity halth needs assessment. Available at: https://www.yakimamemorial.org/pdf/about/communityhna-2019.pdf
World Health Organization. (2017). Household air pollutionThe World's leading environmental health risk. World Health Organization: Geneva, Switzerland.

Wu, C., Chen, X., Cai, Y., Zhou, X., et al. (2020). Risk factors associated with acute respiratory distress syndrome and death in patients with coronavirus disease 2019 pneumonia in Wuhan, China. JAMA Internal Medicine, 180(7), 934-943. https://doi.org/10.1001/jamainternmed. 2020.0994 